\title{
RELAC̣̃̃ES ARTICULADORAS: VIABILIZANDO O USO INSTRUMENTAL DO LOSANGO DIDÁTICO EM SEQUÊNCIAS DE ENSINO-APRENDIZAGEM
}

\author{
PEDRO DONIZETE COLOMBO JUNIOR ${ }^{*}$ \\ https://orcid.org/0000-0003-3324-5859 \\ CIBELLE CELESTINO SILVA"** \\ https://orcid.org/0000-0003-3021-3915
}

RESUMO: Este artigo propõe a instrumentalização do construto didático losango didático proposto por Méheut e Psillos como um guia para organizar a construção de sequências de ensino-aprendizagem a partir do delineamento de relações articuladoras. O losango didático é formado pelos eixos epistêmico e pedagógico, ligando os vértices professor, alunos, mundo material e conhecimento científico. Ocorre que a essência teórica do losango didático não sustenta um caráter instrumental que lhe permita transitar de forma clara e utilitária nos domínios escolares. Propomos relações articuladoras que oferecem suporte para design e desenvolvimento de sequências de ensino-aprendizagem. Ao promover o caráter instrumental do losango didático cria-se oportunidades para romper fronteiras disciplinares, promover atualização metodológica e mediar conhecimentos em um viés de participação ativa do aluno. Palavras-chave: Losango didático. Sequências de ensinoaprendizagem. Relações articuladoras.

RELACIONES ARTICULADORAS: HACER VIABLE EL USO INSTRUMENTAL DEL ROMBO DIDÁCTICO EN SECUENCIAS DE ENSEÑANZA-APRENDIZAJE

RESUMEN: Este artículo propone la instrumentalización del constructo didáctico rombo didáctico propuesto por Méheut y Psillos, como una guía para organizar la construcción de secuencias de enseñanza-aprendizaje, a partir del delineamiento de relaciones articuladoras. El rombo didáctico está formado por los ejes epistémico y pedagógico, que unen los vértices profesor, alumnos,

* Doutor em Ensino de Física pela Universidade de São Paulo. Professor do Programa de Pós-Graduação em Educação da Universidade Federal do Triângulo Mineiro. Líder do Grupo de Estudo e Pesquisa em Educação Não Formal e Ensino de Ciências. E-mail: < pedro.colombo@uftm.edu.br >

* *Doutora em Física pela Universidade Estadual de Campinas, na área de História da Física. Professora do Instituto de Física de São Carlos da Universidade de São Paulo. Líder do Grupo de História, Teoria e Ensino de Ciências. E-mail:< cibelle@ifsc.usp.br >.

I Universidade Federal do Triângulo Mineiro, Uberaba, MG - Brasil.

II Universidade de São Paulo, São Carlos, SP - Brasil. 
mundo material y conocimiento científico. Sin embargo, su esencia teórica no admite un carácter instrumental que le permita transitar de una manera clara y utilitaria en los dominios escolares. Proponemos relaciones articuladoras que apoyen el diseño y desarrollo de secuencias de enseñanza-aprendizaje. Cuando se promueve el carácter instrumental del rombo didáctico, se crean oportunidades para romper límites disciplinarios, promover la actualización metodológica y mediar el conocimiento en un sesgo de participación activa de los estudiantes.

Palabras clave: Rombos didácticos. Secuencias de enseñanzaaprendizaje. Relaciones articuladoras.

\section{ARTICULATING RELATIONSHIPS: ENABLING THE INSTRUMENTAL USE OF THE DIDACTICAL RHOMBUS IN TEACHING-LEARNING SEQUENCES}

ABSTRACT: This paper proposes the use of the didactic construct didactic rhombus proposed by Méheut and Psillos as a guide for organizing the construction of teaching-learning sequences. The didactic rhombus is formed by the epistemic and pedagogical axes, covering the poles teacher, students, material world and scientific knowledge. The theoretical essence of the didactic rhombus does not support its effective application in the school domains. We formulated articulating relations that integrate and support the design and development of teaching-learning sequences. We argue that the use of the didactic rhombus creates opportunities to break disciplinary boundaries, to promote methodological updating of practice, to mediate knowledge towards students' active participation and emancipatory innovation of teaching practice.

Keywords: Didactic rhombus. Teaching-learning sequences. Articulating relations. 


\section{CONSIDERACְÕES INICIAIS}

Dados os impactos da ciência e da tecnologia em nossa vida cotidiana, ao longo das últimas décadas o ensino de ciência tem enfatizado a importância da formação de cidadãos crítico-reflexivos para a vivência em sociedade, além da aprendizagem de conteúdos científicos. Neste cenário, uma vertente em destaque, em especial na área das Ciências da Natureza, é o desenvolvimento e trabalho com sequências de ensino-aprendizagem (SEA) como forma de aproximar a ciência escolar com o cotidiano dos alunos, evidenciando que o conhecimento científico contribui para interpretações do mundo material (VÁZQUEZ-ALONSO et al., 2016; GUISASOLA et al., 2017; KNEUBIL; PIETROCOLA, 2017; MAURÍCIO et al., 2017; SAVINAINEN et al., 2017;; SILVA; COLOMBO JUNIOR, 2017).

A concepção de uma SEA não é algo trivial, muito menos instantâneo. Pelo contrário, deriva de um esforço de longo prazo, pois é um produto que contempla representações de conteúdos inovadores, diferindo-se dos tradicionalmente presentes em livros didáticos e currículos escolares. Para Méheut e Psillos (2004), “[...] uma característica determinante de um SEA é a sua inclusão em um processo evolutivo baseado em pesquisa gradual com o objetivo de entrelaçar perspectivas científica e do estudante" (p. 515).

Méheut e Psillos (2004) defenderam a ocorrência de dois eixos de interesse no processo de design de uma SEA: o epistêmico e o pedagógico, no qual propõem vértices inter-relacionadas: professor, alunos, mundo material e conhecimento científico, configurando o que chamam de losango didático (LD) (Figura 1).

Figura 1. Losango didático

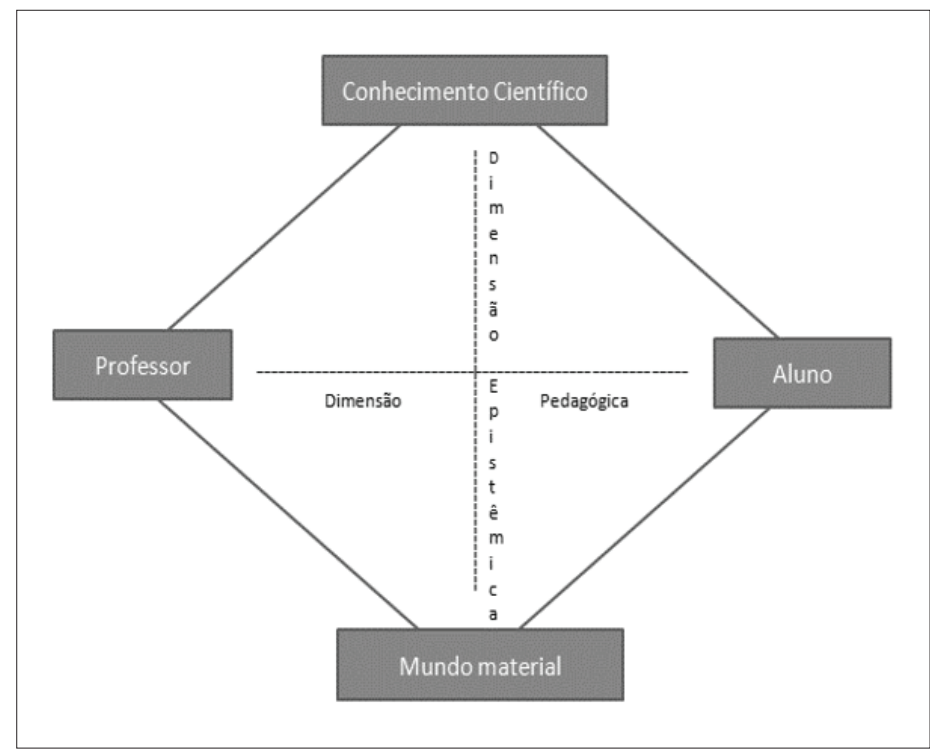

Fonte: Extraído e traduzido de Méheut e Psillos (2004, p. 517) e Méheut (2005, p. 196). 
Segundo os autores, essa representação permite a organização dos elementos presentes no processo de design e validação de uma SEA.

O eixo vertical representa a dimensão epistêmica, isto é, como o conhecimento funciona em relação ao mundo material. Ao longo desse eixo, podemos encontrar premissas sobre métodos científicos, processos de elaboração e validação do conhecimento científico. O eixo horizontal representa a dimensão pedagógica. Encontramos ao longo desse eixo escolhas do professor, tipos de interações entre professores e alunos, e focado no vértice "alunos", podemos encontrar o que se espera sobre as interações entre os alunos (MÉHEUT, 2005, p. 196, tradução nossa).

Não obstante sua relevância teórica, entendemos que apenas o construto LD não sustenta a essencial transposição do aporte teórico para a efetiva aplicação nos domínios escolares e nas análises no campo da pesquisa em educação científica. Isso ocorre, pois, o losango didático não possui um caráter instrumental que lhe permite relacionar de forma clara e utilitária as variáveis do processo ensinoaprendizagem. Scarpa (2015), discutindo aspectos do campo da argumentação em sala de aula, analisou uma sequência didática visando o desenvolvimento de habilidades argumentativas. A autora atribuiu ao LD ações realizadas por professores e alunos (atividades da sequência), explicitando habilidades e competências (em forma de verbos) situadas em suas arestas. O movimento foi olhar da sequência para o LD. A autora menciona que:

Explicitar as ações previstas e representá-las no losango didático permitiu visualizar o desejável equilíbrio que as atividades desenhadas para fomentar a argumentação devem proporcionar entre o papel esperado de professor e o papel esperado de alunos e entre as dimensões epistemológicas e pedagógicas das interações em sala de aula (SCARPA, 2015, p. 26).

Outros pesquisadores também olharam para as derivações do LD frente a construção de SEA. Rodrigues e Ferreira (2011), por exemplo, desenvolveram uma SEA sobre os estados da matéria, atentando para as dimensões epistêmica e pedagógica do LD, ou seja, centrados em seus eixos centrais.

O presente artigo comunga com os mencionados acima, porém caminha no sentido de maximizar as leituras do LD e atribuir-lhe um caráter instrumental. Assim, os objetivos recaem em delinear relações articuladoras nas arestas do LD, de modo que possam fomentar o trabalho de professores e pesquisadores em situações de design e desenvolvimento de sequências de ensino-aprendizagem indo ao encontro da gênese de sua proposta inicial por Méheut e Psillos (2004).

Portanto, indagamos: Quais relações articuladoras podem derivar das arestas do losango didático de modo a propiciar a instrumentalização do mesmo? Quais construtos educacionais (atividades, ações, interações, etc.) podem congregar e contribuir para essa instrumentalização? Dessa forma, propomos um novo olhar para o LD, de modo que este ganhe um caráter instrumental frente à proposição de relações articuladoras que auxiliem pensar a construção de SEAs que contemplem suas dimensões epistêmica e pedagógica. De modo secundário, buscamos também neste artigo 
ilustrar o uso de tais relações na construção e aplicação de uma SEA arquitetada a partir de uma ação de parceria entre o Observatório Dietrich Schiel da USP e escolas públicas de Educação Básica.

\section{AS RELAC̣ÕES ARTICULADORAS E AS DIMENSÕES PEDAGÓGICA E EPISTÊMICA}

As relações articuladoras (RA) podem configurar meios pelos quais o professor organiza sua prática cotidiana com um viés focado nos construtos do losango didático. Em sua essência, as RA são ações que o professor pode desenvolver visando atender as exigências das dimensões didática e pedagógica do processo de ensino e aprendizagem com uma utilidade prática. Portanto, as relações articuladoras podem ser entendidas como entes nas arestas do LD, em uma intrínseca relação de comunicação com suas vertentes didática e epistêmica.

Assim, as relações articuladoras buscam maximizar o entendimento do losango didático frente o planejamento e a construção de SEAs, sendo contributos para o professor (re)pensar tensões colocados entre os vértices do LD em intrínsecas interligações entre arestas e eixos, algo não proposto por Méheut e Psillos (2004) em sua construção original. É justamente nesse sentido que se justifica a demanda por um caráter instrumental, favorecendo e garantindo que as dimensões epistêmica e pedagógica sejam contempladas na construção de SEA. Em meio a tais colocações no presente trabalho consideramos:

(i) construtos teóricos inerentes a elaboração de SEAs. Sobre este aspecto, foram levantadas, analisadas e consideradas diferentes pesquisas que abordaram o trabalho com SEA, considerando especificidades, negociações e exigências epistemológicas inerentes ao campo de conhecimento e exigências condicionantes da relação professor-aluno (BUTY et al., 2004; LINJSE; KLAASSEN, 2004; MÉHEUT, 2005; VILELA et al., 2007; FAZIO et al., 2008; VIIRI; SAVINAINEN, 2008; SOARES; TATO, 2011). Destaca-se também a relevância da construção de SEAs com base em processos contínuos de pesquisa e interlocução professoraluno-conhecimento (MÉHEUT; PSILLOS, 2004) e processos de inovação metodológica e avaliativa a partir do uso e aplicabilidade de SEAs no ensino de ciências (RODRIGUES; FERREIRA 2011).

(ii) recomendações expressas em documentos oficiais, como PCN, PCN+ (BRASIL, 2000; 2006) sobre os elementos que devem estar presentes em aulas de ciências, tais como: leitura, experimentos, interação social, uso das TICs, contextualização e construção coletiva de conhecimentos. E, consonantes a abordagens interdisciplinares, as quais a Lei de Diretrizes e Bases da Educação (BRASIL, 1996) sinaliza como elemento indispensável para que o cidadão entenda e interprete o que se aprende na relação com o que vive.

(iii) proposição de uma inovação emancipatória do trabalho docente (VEIGA, 2003), em uma perspectiva de desenvolvimento e identidade profissional (MARCELO; DOMINGUEZ, 2018), que implica na compreensão do delineamento de relações articuladoras como um processo de rupturas com a 
prática docente arraigadas no chão da escola, suscitando o diálogo e a cooperação mútua entre todos os envolvidos no processo educativo.

A partir de tais considerações, defendemos que ao se promover o caráter instrumental do losango didático criam-se oportunidades para o professor romper fronteiras disciplinares, promover atualização metodológica de sua prática, dialogar com seus pares, mediar conhecimentos em um viés de participação ativa do aluno. Enfim, sinaliza uma inovação emancipatória de sua prática docente.

A seguir apresentamos as relações articuladoras delineadas, as quais buscam a articulação dos pontos vértices do losango didático em suas arestas, delimitando quadrantes de atuação para as SEA (Figura 2). As RA são decodificadas como verbos (conjecturas de ação) que relacionam os vértices professor-mundo material, professor-conhecimento científico, aluno-mundo material, aluno-conhecimento, com isso ampliam a compreensão e utilidade prática das dimensões pedagógica e epistêmica do LD.

Figura 2. Relações articuladoras delineadas nas arestas do losango didático

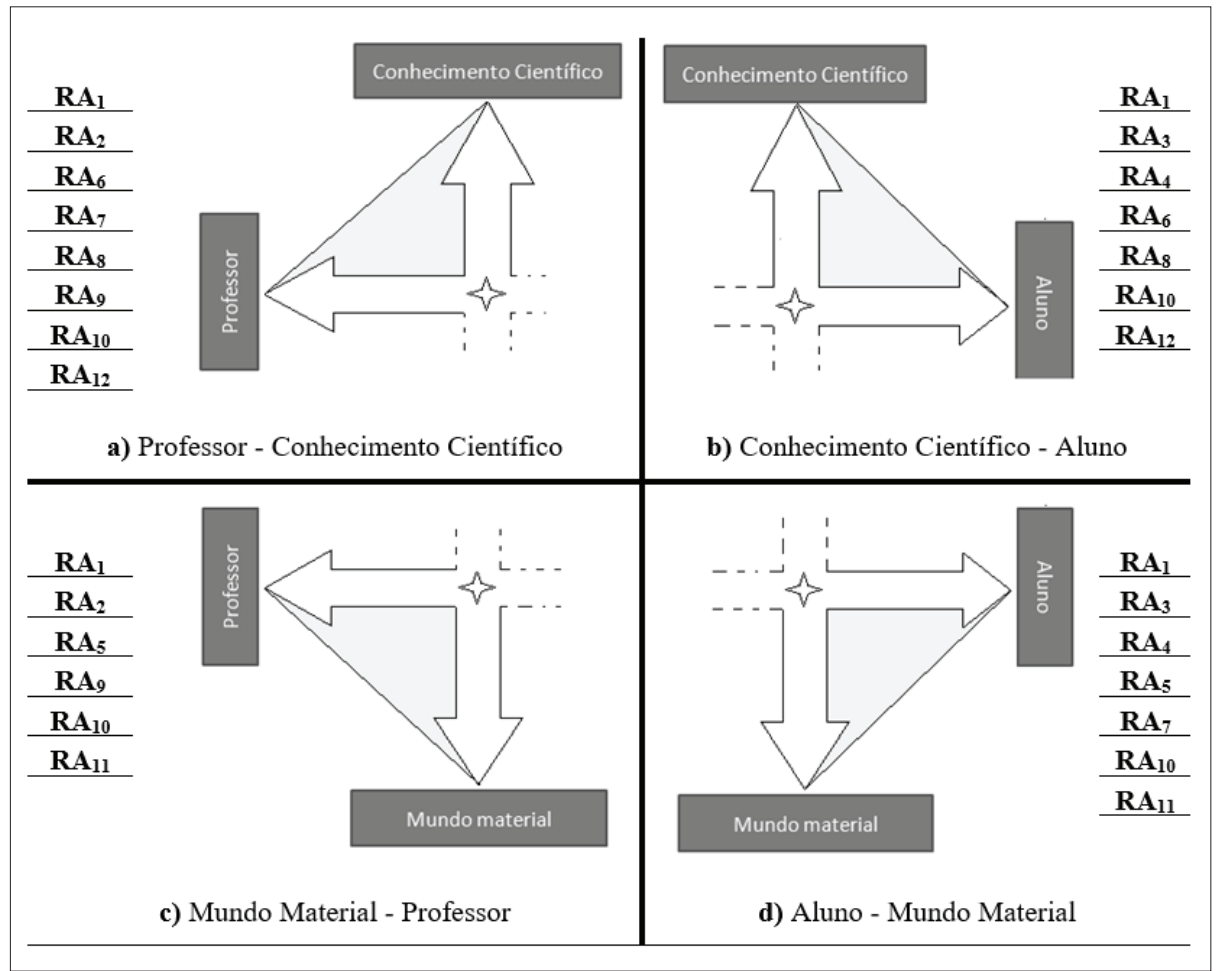

Legenda: $R A_{n}=$ Relação Articuladora " $n$ "; LD = Losango Didático

Fonte: Elaborado pelos autores, 2019.

RA: Promover ambiente de interações mútuas: elaborar atividades a serem desenvolvidas em uma SEA com vista à promoção de interações mútuas e 
múltiplas em sala de aula, com ênfase no aluno como agente ativo no processo de ensino e aprendizagem e o professor como mediador de conhecimentos.

$\mathbf{R A}_{2}$ : Elaborar materiais didáticos acessíveis: propor sempre que possível o uso de materiais/roteiros textuais (livros didáticos e/ou paradidáticos, jornais, revistas, entre outros) de baixo custo e fácil aquisição. Atentar para fatores como contextualização e interdisciplinaridade do ensino frente aos temas de uma SEA.

RA $_{3}$ : Realizar atividades prático-experimentais: sugerir atividades práticoexperimentais a serem realizadas pelos educandos. Empregar um ensino com base em abordagens investigativas e ênfase na participação ativa e argumentativa do educando, já que atividades investigativas possibilitam ao educando levantar e testar hipóteses, interpretar resultados, construir explicações causais, além de socializar com seus pares as descrições de fenômenos estudados (ARAÚJO; ABIB, 2003; CARVALHO, 2013).

RA : Reconhecer estratégias não tradicionais de ensino: prever e adotar estratégias didáticas não tradicionais como elementos motivadores e facilitadores para o processo de ensino e aprendizagem do educando, tais como: show de ciência, cine-aulas, mapas conceituais, cinema, teatro, charge, música, tirinhas, entre outros (COLOMBO JUNIOR; OVIGLI, 2018).

$\mathbf{R A}_{5}$ : Organizar visitas didáticas: incorporar na SEA ações em ambientes extraescolares como forma de maximizar a aprendizagem dos alunos, seja por meio de visitas guiadas, passeios didáticos inclusivos, imersão em telecine. Sobre este aspecto, ressalta-se as ideias dos pesquisadores franceses Allard e Boucher (1991) que sinalizam a importância de se prever três momentos para as visitas didáticas: o antes, fase de preparação para a visita, geralmente realizada na escola; o durante, momento da visita em que há os direcionamentos pretendidos com a visita; e o retorno a sala de aula, momento de retomada dos conteúdos vivenciados pelos educandos.

RA : Valorizar o uso das TICs no cenário educacional: empregar recursos de Tecnologias de Informação e Comunicação (TICs) na elaboração da SEA de modo a facilitar o entendimento dos conceitos científicos trabalhados com os educandos. Nesse caso, podem ser incluídos vídeos, filmes, applets, simuladores, entre outros, como elementos valorizadores das práticas pedagógicas e facilitadores do processo de aprendizagem dos conceitos científicos pelo educando.

RA $_{7}$ : Compreender a articulação entre a sala de aula e o mundo material: aproximar conhecimentos da ciência e do mundo vivencial propondo aos educandos atividades que fomentem a construção do conhecimento científico (eixo epistêmico do conhecimento) como uma (re)leitura contextualizada do mundo presente.

$\mathrm{RA}_{8}$ : Abordar aspectos da história e filosofia e sociologia da ciência: selecionar e apresentar episódios históricos de modo a desmistificar anedotas 
históricas arraigadas pelo senso comum. Demonstrar que o conhecimento científico é histórico e socialmente construído, que sofre transformações, superações e muitos são os caminhos trilhados pelos cientistas. Propor atividades que esclareçam aspectos da natureza da ciência $(\mathrm{NdC})$ e promovam a valorização da cultura material da prática científica.

$\mathbf{R A}_{9}$ : Desenvolver trajetórias de aprendizagem: entender os educandos como detentores de conhecimentos socialmente construídos, os quais carregam especificidades e particularidades intrínsecas a suas vivências. Dessa forma, propor atividades que congreguem diferentes possibilidades e trajetórias de aprendizagem, sendo diversificadas e contemplando diferenças, dificuldades e habilidades individuais.

$\mathbf{R A}_{10}$ : Levantar conhecimentos prévios: organizar atividades que considerarem as preconcepções dos estudantes sobre o conhecimento científico, o questionamento do senso comum e conceitos espontâneos, e suas implicações para o processo de ensino e aprendizagem. Atentar para valorização de saberes populares na construção do conhecimento, a partir das vivências individuais e coletivas dos educandos.

$\mathbf{R A}_{11}$ : Articular o saber docente/discente e o mundo material: construir argumentos, realizar reflexões, organizar ideias e valorizar o conhecimento vivencial-prático do educando na busca pelo entendimento do mundo material e sua íntima relação com o conhecimento científico.

$\mathbf{R A}_{12}$ : Articular o saber docente/discente e o conhecimento científico: propor atividades que esclareçam e problematizem as ideias dos educandos, frente a obstáculos epistemológicos que impeçam o entendimento do conhecimento científico e sua íntima relação com o mundo material.

Por fim, as RA visam articular, dar mobilidade, direcionamento e utilidade prática para o que é planejado pelo mediador (professor) e o que é realizado pelos aprendizes (alunos), em um processo de ensino e aprendizagem pautado nas dimensões epistêmica e pedagógica do losango didático.

\section{RELAC̣ÕES ARTICULADORAS E O DESIGN DE UMA SEA}

Visando ampliar as discussões sobre as relações articuladoras delineadas como forma de instrumentalização do losango didático, apresentamos um recorte de uma investigação realizada no Observatório Dietrich Schiel (ODS/USP) em parceria com professores de escolas públicas do Estado de São Paulo, cujo objetivo foi fundamentar a construção e utilização de uma SEA sobre a temática Física Solar, integrando os contextos educação formal e não formal (COLOMBO JUNIOR, 2014). ${ }^{1}$

O Observatório Dietrich Schiel foi inaugurado em 1986 por ocasião da passagem do cometa Halley, sendo um setor do Centro de Divulgação Científica e Cultural (CDCC/USP). Dentre suas instalações destaca-se a Sala Solar, um espaço 
equipado e devotado ao estudo e divulgação do Sol (AROCA, 2008). O ODS/USP é um espaço de educação não formal, na medida em que propicia a ampliação dos conhecimentos adquiridos em âmbito de escolarização formal (escolar), em especial sobre astronomia aos visitantes, alunos, professores e comunidade de modo geral.

Quatro professores efetivos da rede pública paulista participaram da investigação, sendo que dois ficaram responsáveis por aplicar a SEA elaborada em suas salas de aulas, uma na cidade de Araraquara/SP e outra na cidade de Itirapina/SP. ${ }^{2}$ Inicialmente todos os professores participaram de um curso de aperfeiçoamento docente com carga horária de 40 horas no qual foram trabalhados os construtos teóricos da construção de uma SEA, além das temáticas relacionadas à Física Solar. A SEA foi desenvolvida nas escolas participantes durante o período de três meses, sendo que os dados coletados compreendem o acompanhamento integral dos professores durante o desenvolvimento e aplicação da SEA, gravação em áudio e vídeo das ações realizadas e, entrevistas semiestruturadas com os dois professores participantes, procedimentos amparados em abordagens qualitativas de pesquisa (BOGDAN; BIKLEN, 1994).

O processo de construção da SEA foi do tipo colaborativo, ou seja, amparado em negociações entre professores e pesquisadores, norteados por metodologia construtiva do tipo Design Based Research (DBR), visto que:

[...] Design-Based Research compõe uma metodologia c ooerente que faz a ponte entre pesquisas teóricas e práticas de ensino. Observar o design de uma intervenção e suas disposições específicas como objetos de pesquisa pode produzir explicações robustas de práticas inovadoras e fornecer princípios que podem ser localizados para que outros possam aplicar em novos cenários (DBR, 2003, p. 8, tradução nossa).

Ademais, destaca-se que a construção coletiva da SEA se amparou também em uma sistemática por nós definida de "Ciclos de Reflexão" (CR) (SILVA; COLOMBO JUNIOR, 2017), ou seja, ações contínuas de parceria professorespesquisador, desde preparação docente, passando pela elaboração da SEA até a sua aplicação. Os CR compreendem três etapas interligadas: (i) constituição do grupo de trabalho; (ii) atualização de conteúdos, compartilhamento de ideias, perspectivas e identificação de problemas e soluções, coleta de material já disponível e desenvolvimento da SEA; (iii) aplicação do material desenvolvido, avaliação contínua e reelaboração da SEA.

Seguindo o protocolo da gênese de uma SEA, as ações foram pensadas e repensadas aula a aula sendo a SEA construída a partir de dados da pesquisa, amparadas pelos CR e pelas relações articuladoras delineadas. Destaca-se que essa sistemática foi essencial para atender ambas as partes envolvidas na investigação - a escola por meio dos professores e Universidade por meio dos pesquisadores.

Os professores contribuíram com sua experiência docente e conhecimento do contexto e agentes escolares e o pesquisador com propostas de novas abordagens e estratégias didáticas, bem como atividades e materiais. Buscou-se integrar à SEA o percurso natural dos conteúdos que vinham sendo ministrados pelos professores em sala de aula, respeitando a autonomia dos mesmos. Portanto, a SEA emergiu das negociações entre professores e pesquisadores e das exigências 
epistemológicas inerentes ao campo de conhecimento da Física Solar (dimensão epistêmica) e dos condicionantes de sala de aula (dimensão pedagógica). Assim, no decorrer dos processos de design, aplicação e análise da SEA, o espaço escolar foi respeitado, bem como os interesses investigativos do trabalho realizado. A SEA, configurada por situações de aprendizagem, foi assim definida (Tabela 1):

Tabela 1. SEA desenvolvida e locais de desenvolvimento das atividades.

\begin{tabular}{|c|c|}
\hline $\begin{array}{c}\text { Situação de } \\
\text { Aprendizagem }\end{array}$ & $\begin{array}{l}\text { Conteúdo trabalhado e respectivos ambientes educacionais de ação } \\
\text { EF - Educação Formal (sala de aula); ENF - Educação Não Formal (ODS) }\end{array}$ \\
\hline 01 & $\begin{array}{l}\text { - O Sol e suas estruturas (EF). } \\
\text { - Radiação a, B, y e neutrinos (EF). } \\
\text { - Calculo do diâmetro solar e da distância Sol - Terra (AROCA, 2008) (EF). } \\
\text { - Simular as linhas de campo magnético utilizando limalha de ferro (EF). } \\
\text { - Visualização de manchas solares e outras estruturas do Sol durante visita } \\
\text { ao Observatório (ENF). } \\
\text { - Análise crítica do “Filme 2012" (Columbia Pictures, 2009, EUA) (EF). }{ }^{3}\end{array}$ \\
\hline 02 & $\begin{array}{l}\text { - Construção: espectroscópio amador (SEE/SP, 2009; AZEVEDO, 2008) (EF). } \\
\text { - Visualização do espectro de diferentes fontes de luz na escola (EF). }\end{array}$ \\
\hline 03 & $\begin{array}{l}\text { - Identificação das linhas de absorção do espectro solar no Observatório (ENF). } \\
\text { - Visualizar o espectro de diferentes tipos de lâmpadas no Observatório (ENF). }\end{array}$ \\
\hline 04 & $\begin{array}{l}\text { - Estimando temperatura: fotosfera solar (CANIATO, 1990; AROCA, 2008) (EF). } \\
\text { - Calculando a potência irradiada pelo Sol (AROCA, 2008) (EF). }\end{array}$ \\
\hline 05 & $\begin{array}{l}\text { - Identificação de estrelas a partir de seus espectros e usando Applets (EF e ENF). } \\
\text { - Verificação das Leis de Kirchhoff e das transições eletrônicas no átomo de } \\
\text { Bohr com o uso de Applets (EF). }\end{array}$ \\
\hline
\end{tabular}

Fonte: Elaborado pelos autores, 2019.

É oportuno ressaltar que não é objetivo deste artigo discutir os processos de aprendizagem oriundos da aplicação da SEA em sala de aula. Assim, neste momento buscamos exemplificar o uso das RA na construção de uma SEA. Para atingir tal objetivo, as análises realizadas tiveram como base o acompanhamento ininterrupto das ações dos professores no design e aplicação da SEA nas escolas, além de entrevistas com os mesmos sobre a leitura que faziam das ações/atividades que vinham realizando no trabalho com a SEA. 


\section{AS RELAC̣ÕES ARTICULADORAS NO MATERIAL DIDÁTICO DA SEA}

Pelas análises realizadas, as atividades presentes na SEA desenvolvida em parceria com os professores e aplicada em sala de aula e no Observatório Dietrich Schiel incorporaram as relações articuladoras propostas. As atividades favoreceram as RA no sentido em que propiciaram novos caminhos para a aproximação entre o conhecimento científico e o mundo material $\left(\mathrm{RA}_{7}\right)$, articulações com os saberes dos alunos $\left(\mathrm{RA}_{11}\right.$ e $\left.\mathrm{RA}_{12}\right)$ e desenvolvimento de atividades experimentais $\left(\mathrm{RA}_{3}\right)$. Implementaram novas estratégias didáticas no ensino, por exemplo, com o uso de Applets no trabalho com os alunos (RA) e abordagem teatral no ensino de física $\left(\mathrm{RA}_{4}\right)$. A SEA concretizou as RA no momento em que a parceria e complementariedade dos ambientes formal e não formal possibilitou a realização de atividades difíceis de serem realizadas na escola, por exemplo, a observação do espectro solar de absorção (realizado na Sala Solar) ( $\mathrm{RA}_{7}$ e RA $\mathrm{R}_{5}$ ).

Com relaçãoà dimensão pedagógica do losango didático, destacamos que a $\mathrm{RA}_{1}$ (promover ambiente de interações mútuas) foi a mais frequente no desenvolvimento das situações de aprendizagem trabalhadas com os alunos. A dimensão pedagógica reflete um movimento de interação professor-aluno, sendo sua ocorrência desejável para o processo de ensino e aprendizagem. Com isso, a predominância está relacionada à postura docente frente às atividades desenvolvidas, já que em todas as atividades (em sala de aula e no Observatório) os alunos desempenharam papel ativo na construção do conhecimento, ou seja, as ações passaram de um viés expositivo para um viés dialogado e prático. A integração da escola com o ambiente não formal também revelou a intensificação das relações interpessoais entre aluno e professores reforçando a dimensão pedagógica do losango didático.

Por outro lado, as $\mathrm{RA}_{5}$ e RA foram as que apresentaram as menores frequências frente às situações de aprendizagem propostas na SEA. A relação $\mathrm{RA}_{6}$, que remete ao uso das TICs foi implementada no retorno à sala de aula com atividades desenvolvidas no laboratório de informática. Já a relação RA 5 parece na atividade de identificação das linhas de absorção do espectro solar em visita ao Observatório, sendo ambas ações pontuais (porém não menos importantes). Outras ações também reforçam as ações do professor na dimensão pedagógica, tais como: construção e uso de um espectroscópio amador, estimativa da temperatura da fotosfera solar e potência irradiada pelo Sol, análise crítica de trechos do "Filme 2012", uso de dramatização teatral com a encenação pelos alunos de textos sobre o Sol e a física solar, e uso de Applets no laboratório de informática das escolas. Todas as atividades mencionadas contemplam relações articuladoras que instrumentalizaram o losango didático favorecendo mobilidade e utilidade prática para o trabalho do professor e, extrapolando, permitindo uma inovação emancipatória docente.

Considerando a dimensão epistêmica do losango didático, as relações articuladoras mais contempladas foram a aproximação entre o conhecimento científico e o mundo material, como nas atividades de espectroscopia na Sala Solar e determinação da temperatura da fotosfera ( $\mathrm{RA}_{2}$ e $\left.\mathrm{RA}_{3}\right)$, assim como a articulação do saber discente com o mundo material e com o conhecimento científico $\left(\mathrm{RA}_{7}\right.$, $\mathrm{RA}_{11}, \mathrm{RA}_{12}$ ). Aspectos históricos, filosóficos e sociológicos da ciência presentes na relação $\mathrm{RA}_{8}$ foram contemplados a partir da discussão sobre a radiação de 
corpo negro e ideias iniciais da física quântica no "final" do século XIX, bem como no estudo da parceria entre Kirchhoff e Bunsen na identificação dos elementos químicos e construção de um espectroscópio. Perceber tais atividades com as lentes das relacões articuladoras delineadas permitem uma nova visão da dimensão epistêmica do losango didático, uma vez que ao tomar consciência da ponte mundo material-conhecimento científico, o professor passa a compreender a aproximação para prática docente desenvolvida com os alunos.

A tabela 2 sintetiza as análises acima, evidenciando que as atividades integrantes da SEA (ou seja, as situações de aprendizagem) contemplaram todas as RA delineadas, sendo estas importantes ferramentas para auxiliar os professores no (re)pensar atividades no design de uma SEA em sala de aula.

Tabela 2. RA como fomento construtivo da SEA e instrumentalizador do LD.

\begin{tabular}{|c|c|}
\hline $\begin{array}{l}\text { Relações } \\
\text { Articuladoras }\end{array}$ & Atividade integrantes da SEA \\
\hline $\mathrm{RA}_{1} ; \mathrm{RA}_{3} ; \mathrm{RA}_{7}$ & Cálculo: diâmetro solar e distância Sol-Terra \\
\hline $\mathrm{RA}_{1} ; \mathrm{RA}_{3} ; \mathrm{RA}_{5} ; \mathrm{RA}_{7}$ & $\begin{array}{l}\text { Observação do Sol e algumas estruturas usando a luneta Grubb do } \\
\text { Observatório. O Sol e suas estruturas }\end{array}$ \\
\hline $\mathrm{RA}_{1} ; \mathrm{RA}_{7} ; \mathrm{RA}_{8}$ & $\begin{array}{l}\text { Experimento de determinação da temperatura do Sol lo Sol como } \\
\text { corpo negrol e discussão do surgimento da mecânica quântica. } \\
\text { Construção: espectroscópio amador. }\end{array}$ \\
\hline $\mathrm{RA}_{3} ; \mathrm{RA}_{10}$ & Simulação das linhas de campo magnético utilizando limalha de ferro \\
\hline $\mathrm{RA}_{6}$ & $\begin{array}{l}\text { Verificação das Leis de Kirchhoff e átomo de Bohr com o uso de } \\
\text { Applets. Identificação de estrelas e espectros e usando Applets }\end{array}$ \\
\hline $\mathrm{RA}_{1} ; \mathrm{RA}_{5} ; \mathrm{RA}_{7}$ & $\begin{array}{l}\text { Visualização e discussão da projeção de manchas solares e outras } \\
\text { estruturas do Sol }\end{array}$ \\
\hline $\mathrm{RA}_{1} ; \mathrm{RA}_{4} ; \mathrm{RA}_{11} ; \mathrm{RA}_{12}$ & Análise crítica de trechos do filme “2012”. Radiação a, B, y e neutrinos \\
\hline $\mathrm{RA}_{2} ; \mathrm{RA}_{4} ; \mathrm{RA}_{7}$ & $\begin{array}{l}\text { Elaboração, interpretação e encenação de texto teatral sobre o Sol. } \\
\text { Estratégia didática não tradicional para o ensino. }\end{array}$ \\
\hline
\end{tabular}

Fonte: Elaborado pelos autores, 2019.

O losango didático representa um esquema didático que descreve o desenho da gênese de uma SEA e as RA propiciam elementos que fomentam seu uso prático no planejamento, construção e investigação da SEA em sala de aula. Contudo, as RA delineadas não esgotam as possibilidades interpretativas do losango didático, apesar de defendermos que podem propiciar um norte para professores e pesquisadores pensarem a construção de uma SEA, para o trabalho docente em sala de aula e, para as investigações em ensino e educação. 


\section{CONSIDERACְÕES FINAIS}

O presente artigo discute uma investigação, que em um primeiro momento buscou propor a instrumentalização do construto didático conhecido como losango didático (LD) a partir do delineamento de relações articuladoras (RA). Tal ação visou propiciar a professores e pesquisadores um norte para o processo de design e desenvolvimento de sequências de ensino-aprendizagem. Para isso, foram exploradas as arestas de ligação entre os vértices do LD, que têm como ponto de partida as dimensões epistêmica e pedagógica do losango. A motivação para esta investigação partiu da percepção, no decorrer de várias pesquisas e estudos sobre SEA, de que o LD tal como proposto originalmente por Méheut e Psillos (2004) não é aplicável nos domínios escolares sem um aporte norteador que decodifique suas diferentes interligações em ações e atividades.

Em um segundo momento, como forma de demonstrar a proposição ora elucidada, apresentamos uma aplicação das RA na construção de uma SEA em uma pesquisa desenvolvida no Observatório Dietrich Schiel da USP em parceria com escolas públicas. No que se refere ao design da referida SEA, destacamos que este foi um momento importante, visto que as escolhas do que faria parte (ou não) da SEA tinha intrínseca relação com as RA delineadas para auxiliar o professor nesta empreitada.

No que se refere ao primeiro momento - o olhar para o LD e as RA delineadas - destacamos que muitos dos pressupostos teóricos para o ensino de ciências estão contemplados nas RA delineadas na forma de ações e atividades. Com isso, as 12 (doze) RA delineadas transitam pelos vértices do LD e guiam a construção de SEA. São elas: promover ambiente de interações mútuas, elaborar materiais didáticos acessíveis, realizar atividades prático-experimentais, reconhecer estratégias não tradicionais de ensino, organizar visitas didáticas, valorizar o uso das TICs no cenário educacional, compreender a articulação entre a sala de aula e o mundo material, abordar aspectos da história e filosofia e sociologia da ciência, desenvolver trajetórias de aprendizagem, levantar conhecimentos prévios, articular o saber docente/discente e o mundo material, e articular o saber docente/discente e o conhecimento científico.

As relações apresentadas possuem um caráter geral no sentido de guiar a construção de SEA, de temáticas diversas, que considerem o LD como base teórica e que visem a aproximação da ciência escolar com o cotidiano do aluno. Contudo, é importante ressaltar que as RA delineadas possuem especificidades e restrições, pois não foram pensadas para uma sequência didática qualquer, mas sim para sequências de ensino e aprendizagem (SEA) que busquem evidenciar que o conhecimento científico contribui para interpretações do mundo material. Neste sentido, o cuidado a ser tomado é atentar para a base teórica que sustenta a construção de SEA, em especial o fato de que estas evoluem progressivamente dentro de um gradual processo de ensino e pesquisa.

No que se refere ao uso das RA, segundo momento da pesquisa em tela, destaca-se que o professor é por elas guiado a enxergar a mobilidade e a utilidade prática das ações previstas nas dimensões pedagógica e epistêmica do LD, dando uma nova perspectiva para a construção e acompanhamento da SEA desenvolvida no Observatório Dietrich Schiel da USP e em escolas públicas, revelando mais 
possibilidades do que dificuldades e limitações para o trabalho docente. $\mathrm{Na}$ vertente epistêmica, notamos que algumas relações articuladoras, como as $\mathrm{RA}_{9}$ e RA ${ }_{10}$, permitem enxergar os educandos como detentores de conhecimentos e não como tábulas rasas. Apesar disso, a aplicação da SEA em sala de aula foi uma ação de extrema importância, visto que, em sua essência, uma SEA é construída em um continuum alimentada por dados de pesquisa. Desta forma, as discussões e socializações entre professores e pesquisadores guiavam o caminho a ser seguido pela SEA, alterando, incluindo e excluindo temáticas e atividades que atendiam aos pressupostos das RA delineadas.

Do exposto acima, concluímos que na dimensão pedagógica as RA favoreceram, em menor ou maior proporção, as interações entre professor-aluno, pesquisador-professor, aluno e seus pares. Enquanto que na dimensão epistêmica favoreceram a aproximação entre o conhecimento científico e o mundo material, fomentando um trabalho docente que propiciou a participação ativa dos alunos na construção do conhecimento (interação e argumentação), apreciação das preconcepções dos estudantes, articulação do saber científico e o mundo vivencial dos estudantes, articulação entre os espaços formais e não formais para a educação científica e uso das TICs no ensino.

Portanto, as RA têm um alcance para além da SEA apresentada, servindo para o pensar sequências de ensino aprendizagem em diferentes áreas do conhecimento. As RA também permitem vislumbrar a aproximação da ciência escolar com o cotidiano do aluno, promovem o conhecimento científico como contribuinte para interpretações do mundo material e; contribuem para a atribuição de um caráter instrumental ao losango didático, de modo que sua observância no contexto escolar possa aderir às práxis educativas e relações professor-aluno. Tais relações contribuem para a prática docente e para a área de pesquisa em ensino e educação, em especial para investigações envolvendo o design e desenvolvimento de SEA no contexto escolar.

\section{AGRADECIMENTOS}

Os autores agradecem às escolas e aos professores participantes da pesquisa e, ao Programa de Pós-Graduação Interunidades em Ensino de Ciências da Universidade de São Paulo. Pelo apoio financeiro, o primeiro autor agradece à FAPESP (processo no 2010/16843-9) e a segunda autora ao CNPq.

\section{REFERÊNCIAS}

ALLARD, M.; BOUCHER, S. Le musée et l'école. (Cahiers du Québec, 98), Québec: Hurtubise HMH, 1991, 140p.

ARAUJO, M. S. T.; ABIB, M. L. V. S. Atividades Experimentais no Ensino de Física: Diferentes Enfoques, Diferentes Finalidades. Revista Brasileira de Ensino de Física, v.25, n. 2, 2003, p.176-194.

AROCA, S. C. Ensino de física solar em um espaço não formal de educação. 173f. 2008. Tese (Doutorado em Ciências), Instituto de Física de São Carlos, Universidade de São Paulo, São Paulo, Brasil, 2008. 
AZEVEDO, M. C. P. S. Situações de ensino - aprendizagem. Análise de uma sequência didática de física a partir da Teoria das Situações de Brousseau. 284f. 2008. Dissertação (Mestrado em Educação), Faculdade de Educação, Universidade de São Paulo, São Paulo, Brasil, 2008.

BOGDAN, R. C.; BIKLEN S. K. Investigação qualitativa em educação: uma introdução a teoria e aos métodos. Porto: Porto S.A., 1994 (Coleção Ciências da Educação).

BRASIL. Lei de Diretrizes e Bases da Educação (LDB). Lei no 9394/96, de 20 de dezembro de 1996. Brasília: MEC, 1996.

BRASIL. Parâmetros Curriculares Nacionais (PCN). Ciências da Natureza, Matemática e suas Tecnologias. Brasília, MEC, 2000.

BRASIL. Orientações educacionais complementares aos Parâmetros Curriculares Nacionais (PCN+). Ciências da Natureza, Matemática e suas Tecnologias. Brasília, MEC, 2006.

BUTY, C.; TIBERGHIEN, A.; LE MARECHAL, J. Learning hypotheses and an associated tool to design and to analyse teaching-learning sequences. International Journal of Science Education, Special Issue, v. 26, n. 5, p. 579-604, 2004.

CANIATO, R. O céu. São Paulo: Editora Ática, 1990.

CARVAlHO, A. M. P. Ensino de Ciências e a proposição de sequências de ensino investigativas. In: Carvalho, A. M. P. (org.). Ensino de Ciências por Investigação. $1^{a}$ ed. São Paulo: Cengage Learning, 2013.

COLOMBO JUNIOR, P. D. Inovações curriculares em ensino de física moderna: investigando uma parceria entre professores e centro de ciências. 2014. 254f. Tese (Doutorado em Ensino de Ciências - Ensino de Física), Universidade de São Paulo, São Paulo, 2014.

COLOMBO JUNIOR, P. D.; OVIGLI, D. F. A interface arte-ciência-cultura como forma de inovar a formação inicial de professores de Física. Revista Iberoamericana de Educación, v. 77, n. 1, p. 97-120, 2018.

DESIGN BASED RESEARCH (DBR, Collective). An Emerging Paradigm for Educational Inquiry. Educational Researcher, v. 32, n. 1, p. 5-8, 2003.

FAZIO, C.; GUASTELlA, I.; SPERANDEO-MINEO, R. M.; TARANTINO, G. Modelling Mechanical Wave Propagation: Guidelines and experimentation of a teaching-learning sequence. International Journal of Science Education, v. 30, n. 11, pp. 1491-1530, 2008.

GUISASOLA, J.; ZUZA, K.; AMETLLER, J.; GUTIERREZ-BERRAONDO, J. Evaluating and redesigning teaching learning sequences at the introductory physics level. Physical Review Physics Education Research, v. 13, n. 2, 2017.

KNEUBIL, F. B.; PIETROCOLA, M. A pesquisa baseada em design: visão geral e contribuições para o ensino de ciências. Investigações em Ensino de Ciências, v. 22, n. 2, p. 1-16, 2017.

LIJNSE, P.; KLAASSEN, K. Didactical structures as an outcome of research on teaching-learning sequences? International Journal of Science Education, Special Issue, v. 26, n. 5, 2004, pp. 537-554.

MARCELO, C.; DOMINGUEZ, G. C. ¿Quién soy yo como maestro? Construcción de la identidad profesional en docentes principiantes. In: Identidad profesional docente. MAYO, I. C.; TARDIF, M. (Coord.). Madri: Narcea S.A. de ediciones, 2018, p. 45-56. 
MAURÍCIO, P.; VALENTE, B.; CHAGAS, I. A Teaching-Learning Sequence of Colour Informed by History and Philosophy of Science. International Journal of Science and Mathematics Education, v. 15, n. 7, p. 1177-1194, 2017.

MEHEUT, M.; PSILLOS, D. Teaching-learning sequences: aims and tools for science education research. International Journal of Science Education, Special Issue, v. 26, n. 5, p. 515-535, 2004.

MEHEUT, M. Teaching-learning sequences tools for learning and/or research. In: BORESMA, K.; GOEDHART, M; JONG, O.; EIJKELHOF, H (ed.). Research and Quality of Science Education. Netherlands: Springer, p. 195-207, 2005.

RODRIGUES, G. M.; FERREIRA, H. S. Elaboração e análise de sequências de ensino aprendizagem sobre os estados da matéria. In.: VIII Encontro Nacional de Pesquisa em Educação em Ciências (ENPEC), p. 1-12, Campinas, São Paulo, Brasil, 2011. Disponível em: < http://www.nutes. ufrj.br/abrapec/viiienpec/resumos/R0234-2.pdf>. Acesso em: 13 out. 2018.

SAVINAINEN. A.; MÄKYNEN. A.; NIEMINEN, P.; VIIRI, J. The Effect of Using a Visual Representation Tool in a Teaching-Learning Sequence for Teaching Newton's Third Law. Research in Science Education, v. 47, n. 1, p. 119-135, 2017.

SCARPA, D. L. O papel da argumentação no ensino de ciências: lições de um workshop. Revista Ensaio - Pesquisa em Educação em Ciências, v. 17, n.spe, p. 15-30, 2015.

SEE/SP. Proposta Curricular do Estado de São Paulo. Caderno do Professor: Física. Secretaria de Estado da Educação de São Paulo, São Paulo, apostila v. 3, p. 25-29, 2009.

SILVA, C. C.; COLOMBO JUNIOR, P. D. Teaching Solar Physics in a partnership between formal and non-formal education. In: PIETROCOLA, M; GURGEL, I. (org.). Crossing the Border of the Traditional Science Curriculum: Innovative Teaching and Learning in Basic Science Education. 1ed. Rotterdam: Sense Publishers, v. único, p. 127-141, 2017.

SOARES, R.; TATO, A. Transposição Didática, a utilização das Teaching Learning Sequences (TLS) como ferramentas de otimização. In.: XIX Simpósio Nacional de Ensino de Física (SNEF), Manaus, Amazonas, Brasil, 2011. Disponível em: < http://www.sbf1.sbfisica.org.br/eventos/snef/ xix/sys/resumos/T0316-2.pdf>. Acesso em: 13 out. 2018.

VÁZQUEZ-ALONSO, A.; APONTE, A.; MANASSERO, M. A.; MONTESANO, M. A teachinglearning sequence on a socio-scientific issue: analysis and evaluation of its implementation in the classroom. International Journal of Science Education, v. 38, n. 11, p. 1727-1746, 2016.

VEIGA, I. P. A. Inovações e projeto político-pedagógico: uma relação regulatória ou emancipatória? Caderno CEDES, v. 23, n. 61, p. 267-281, 2003.

VILELA, C. X.; GUEDES, M. G. M.; AMARAL, E. M. R.; BARBOSA R. M. N. Análise da elaboração e aplicação de uma sequência didática sobre o aquecimento global. In: VI Encontro Nacional de Pesquisa em Educação em Ciências, Florianópolis, Santa Catarina, Brasil, 2007. Disponível em: <http://www.nutes.ufrj.br/abrapec/vienpec/CR2/p710.pdf>. Acesso em: 13 out. 2018.

VIIRI, J.; SAVINAINEN, A. Teaching-learning sequences: A comparison of learning demand analysis and educational reconstruction. Latin-American Journal of Physics Education, v. 2, n. 2, 2008, pp. 80-86. 


\section{NOTAS}

1 Pesquisa realizada com o apoio da Fundação de Amparo à Pesquisa do Estado de São Paulo (FAPESP).

2 Esta ocorrência é justificada pelo fato de que apenas dois professores ministravam aulas para o $3^{\circ}$ bimestre do $3^{\circ}$ ano do ensino médio, momento escolhido conjuntamente entre professores e pesquisador para que a temática de Física Solar fosse abordada com os alunos.

3 O "Filme 2012" (Columbia Pictures Industries, Inc.), com direção de Roland Emmerich e produção de Harald Kloser, Mark Gordon e Larry J. Franco foi lançado no Brasil em novembro de 2009. O filme retrata um cenário em que o planeta Terra será aniquilado devido a altas concentrações de radiação (e neutrinos solares) oriundas de explosões solares, as quais estão interagindo e aquecendo o núcleo da Terra. Então, a partir de avisos de um cientista americano líderes mundiais começam uma mobilização oculta visando a sobrevivência de membros da sociedade.

\section{Submetido em 18/02/2019}

Aprovado em 03/10/2019

\section{Contato:}

A/C Prof. Dr. Pedro Donizete Colombo Junior

Universidade Federal do Triângulo Mineiro (UFTM)

Programa de Pós-Graduação em Educação (PPGE)

Rua Vigário Carlos, $100 \cdot 5^{\circ}$ andar - Sala 538 Bairro Abadia

CEP 38.025-350 - Uberaba, MG - Brasil 